\title{
Microstructural morphology effects on fracture resistance and crack tip strain distribution in Ti-6Al-4V alloy for orthopedic implants
}

\author{
I. Cvijović-Alagića ${ }^{\mathrm{a}, *}$, N. Gubeljak ${ }^{\mathrm{b}}$, M. Rakin ${ }^{\mathrm{c}}$, Z. Cvijovićc ${ }^{\mathrm{c}}, \mathrm{K}$. Gerić ${ }^{\mathrm{d}}$ \\ a Institute of Nuclear Sciences “Vinča”, University of Belgrade, P.O. Box 522, 11001 Belgrade, Serbia \\ ${ }^{\mathrm{b}}$ Faculty of Mechanical Engineering, University of Maribor, Smetanova 17, Maribor, Slovenia \\ ${ }^{\mathrm{C}}$ Faculty of Technology and Metallurgy, University of Belgrade, Karnegijeva 4, 11120 Belgrade, Serbia \\ ${ }^{\mathrm{d}}$ Faculty of Technical Sciences, University of Novi Sad, Trg Dositeja Obradovića 6, 21000 Novi Sad, Serbia
}

\section{A R T I C L E I N F O}

\section{Article history:}

Received 21 May 2013

Accepted 30 July 2013

Available online 8 August 2013

\section{Keywords:}

Ti-6Al-4V

Microstructural morphology

Tensile properties

Fracture mechanics

Digital stereometry

Normalization method

\begin{abstract}
A B S T R A C T
The effects of microstructural morphology on the fracture behavior of Ti-6Al-4V ELI (extra-low impurity) alloy in two different heat treatment conditions were examined. Alloy was solution treated above ( $\beta$ ST) and below $(\alpha+\beta$ ST) $\beta$ transus temperature followed by furnace cooling (FC) in order to obtain the fully lamellar and equiaxed microstructures. Tensile and fracture toughness tests were conducted. The crack tip opening displacement (CTOD) and strain distribution near the crack tip were measured on the compact tension (CT) specimen surface by digital stereometric method. The crack propagation resistance $(C T O D-R)$ curves were developed by applying the modified normalization method and critical CTOD values were determined. To identify the microstructural length scale controlling the fracture resistance of this alloy, the crack propagation path and fracture surface morphology were evaluated. It was found that the reduction in the characteristic microstructural dimension of an order of magnitude and significant change in the $\alpha$ phase aspect ratio contribute to drastic increase in the tensile properties and decrease in the crack initiation and propagation resistance. The fully lamellar microstructure displays slightly better biocompatibility because of the lower elastic modulus and superior fracture resistance. The enhanced crack propagation resistance of this microstructure is associated with the larger propensity for crack tip tortuousity, due to the coarser microstructural dimensions (lamellar colony size vs. primary $\alpha$ grain size). The difference in the crack propagation modes affects the shape and size of the actual crack tip strain distribution. These results were discussed correlating the complex multiple fracture mechanisms with the stress state in two microstructures.
\end{abstract}

(c) 2013 Elsevier Ltd. All rights reserved.

\section{Introduction}

The mechanical properties of biomedical titanium alloys are important criteria of their applications for load-bearing orthopedic devices. The Ti-6Al-4V alloy is extensively used in the manufacturing of orthopedic implants, due to its good combination of tensile properties, fatigue strength and fracture toughness [1-4]. However, it is observed that relatively high elastic modulus and variable fracture resistance of this two-phase $\alpha+\beta$ titanium alloy are often related to further bone degradation and premature implant failure [3-6]. The knowledge of fracture behavior and tailored design of $\mathrm{Ti}-6 \mathrm{Al}-4 \mathrm{~V}$ alloy are essential to prolongate implants service life.

The fracture properties of titanium alloys are quite sensitive to the microstructural features, depending on the chemical composition and processing conditions. Hence, it is possible to optimize the

\footnotetext{
* Corresponding author. Tel.: +381 113408 606; fax: +381 113408224 .

E-mail address: ivanac@vinca.rs (I. Cvijović-Alagić).
}

crack initiation and propagation resistance of such an alloy by impurity content reduction and proper thermomechanical or heat treatment [2,4,7-11]. There is extensive literature on the role of microstructural morphology in affecting the fracture resistance of $\alpha+\beta$ titanium alloys $[4,7,8,10-20]$. It is established that alloy with a fully lamellar microstructure has superior fracture toughness compared to ones with an equiaxed or martensitic microstructure. At the same time lamellar microstructure shows inferior high cycle fatigue resistance. On the other hand, a bimodal microstructure provides the highest high cycle performance.

The important microstructural parameters determining the effective slip length and hence the mechanical properties are the $\beta$ grain size, the $\alpha$ colony size, width of the $\alpha$ lamellae, the aspect ratio of $\alpha$ phase, the volume fraction and size of equiaxed primary $\alpha$ phase $[7,8,12,20]$. For the acicular microstructure such as lamellar and martensitic microstructure, the enhancement of fracture toughness arises from the microcrack propagation in a zig-zag way along the $\alpha$ platelets or platelet colony boundaries $[7,8,18]$. Many studies reported that coarsening of acicular $\alpha$ phase 


\section{Nomenclature}

CTOD crack tip opening displacement ( $\mathrm{mm})$

$C T O D-R$ ( $R$ curve) crack propagation resistance curve

$R_{m} \quad$ ultimate tensile strength (MPa)

$R_{p 0.2} \quad$ yield strength at $0.2 \%$ offset (MPa)

$E \quad$ elastic modulus (GPa)

A elongation to failure (\%)

$n \quad$ strain hardening exponent

$\delta_{5} \quad$ crack-tip opening displacement defined for a gauge length of $5 \mathrm{~mm}(\mathrm{~mm})$

F applied load $(\mathrm{kN})$

$\Delta a \quad$ crack extension $(\mathrm{mm})$

CMOD crack mouth opening displacement ( $\mathrm{mm}$ )

$C M O D_{L L D} \quad$ CMOD determined using load-line displacement measurement (mm)

$\begin{array}{ll}C M O D_{p l} & \begin{array}{l}\text { CMOD plastic component }(\mathrm{mm}) \\ \text { normalized load }\left(\mathrm{kN} / \mathrm{mm}^{2}\right)\end{array} \\ P_{N i} & \begin{array}{l}\text { crack tip opening displacement at crack initiation } \\ (\mathrm{mm})\end{array} \\ C T O D_{i} & \begin{array}{l}\text { crack extension of } 0.2 \mathrm{~mm} \text { after crack tip blunting } \\ (\mathrm{mm})\end{array} \\ C T O D_{0.2 / B} & \text { stretched zone width }(\mu \mathrm{m}) \\ \text { CZW } & \text { crack opening displacement }(\mathrm{mm}) \\ C O D & \text { maximum plastic zone dimension }(\mu \mathrm{m}) \\ r_{\max } & \text { maximum applied load }(\mathrm{kN}) \\ F_{\max } & \text { hydrostatic stress }(\mathrm{MPa}) \\ \sigma_{m} & \text { primary } \alpha \text { grain size }(\mu \mathrm{m}) \\ \lambda_{\alpha} & \text { spacing between primary } \alpha \text { grains }(\mu \mathrm{m}) \\ \lambda_{\beta} & \end{array}$

$C_{M O D} \quad$ CMOD plastic component (mm)

$P_{N i} \quad$ normalized load $\left(\mathrm{kN} / \mathrm{mm}^{2}\right)$

crack tip opening displacement at crack initiation

$(\mathrm{mm})$ crack opening displacement (mm) maximum plastic zone dimension $(\mu \mathrm{m})$ hydrostatic stress (MPa) spacing between primary $\alpha$ grains $(\mu \mathrm{m})$ increases crack deflection and fracture toughness $[17,20]$. This implies that the width of $\alpha$ platelets is most critical parameter in controlling the fracture toughness of alloys with acicular microstructure. Some authors, on the other hand, pointed out that the $\alpha \mid \beta$ colonies are predominant microstructural parameters resulting in an increase in the crack tip plastic zone [7,8]. In the equiaxed microstructure, the crack path is almost linear along primary $\alpha / \alpha$ or primary $\alpha /$ transformed $\beta$ phase boundaries contributing to the decrease of fracture toughness $[13,18,20]$. Since the primary $\alpha$ phase boundaries become obstacles to microcrack propagation, the crack tip plasticity decreases as the size of the primary $\alpha$ phase decreases. The aspect ratio of primary $\alpha$ phase is another parameter which controls the fracture behavior of alloy with equiaxed microstructure [20].

From these observations, it can be concluded that the assessment of strain distribution around the crack tip is of great importance in determination of fracture resistance. In order to obtain the data for calculating fracture mechanics parameters, it is necessary to monitor deformation value ahead of the crack tip which constantly changes with crack growth. There is also problem in evaluating the fracture resistance of $\mathrm{Ti}-6 \mathrm{Al}-4 \mathrm{~V}$ alloy, relating to the damage mechanisms associated with the cracking process.

In this study, the fracture toughness measured by the crack tip opening displacement (CTOD) and development of a crack propagation resistance curve ( $R$ curve) were investigated for an extra-low impurity (ELI) Ti-6Al-4V alloy with microstructures obtained under different heat treatments. The values of fracture parameters and crack extension were determined using three-dimensional (3D) surface displacement measurements. The stereometric measurements were also applied to obtain the actual crack tip deformation fields. The resistance curves $(C T O D-R)$ were directly developed using the newly proposed method based on the normalization procedure [21]. In addition, the configuration of crack tip during loading and fracture surface morphology were examined. Finally, the relationship between microstructural parameters and fracture properties of investigated alloy was discussed.

\section{Experimental procedure}

Two distinct microstructures, fully lamellar and equiaxed, were produced in Ti-6Al-4V ELI alloy through control of solution annealing temperature. Alloy bars (38 $\mathrm{mm}$ in diameter) supplied by Krupp VDM GmbH, Germany, were solution treated (ST) above the $\beta$ transus temperature at $1000{ }^{\circ} \mathrm{C}(\beta \mathrm{ST})$ and below the $\beta$ transus temperature at $750{ }^{\circ} \mathrm{C}(\alpha+\beta \mathrm{ST})$ for $1 \mathrm{~h}$ and then furnace cooled (FC). Heat treatment was performed in a protective argon atmosphere.
The microstructures were examined using the secondary electron imaging (SEI) mode of a scanning electron microscope (SEM) operating at $25 \mathrm{keV}$. The specimens for SEM observations were polished and etched in Kroll's reagent ( 10 vol.\% $\mathrm{HF}$ and 5 vol.\% $\mathrm{HNO}_{3}$ in water). The volume fraction of phases and their geometrical parameters were estimated by image analysis according to the ASTM: E 1245-03 standard.

Mechanical testing was conducted in a servo hydraulic Instron 1255 testing machine supplied with Control Panel $8500+$ computational data acquisition system for 3D optical measurements and numerical analysis. Micro tension specimens (MTS), heaving geometry as shown in Fig. 1a, were used for carrying out tensile tests in accordance with the ASTM: E8/E8M-11 standard at room temperature as described previously [22,23]. Ultimate tensile strength $\left(R_{m}\right)$, yield strength at $0.2 \%$ offset $\left(R_{p 0.2}\right)$, elastic modulus $(E)$, elongation to failure $(A)$ and strain hardening exponent $n$ in the Ramberg-Osgood equation [24] were determined.

Dimensions of the compact tension (CT) specimen for fracture toughness tests are given in Fig. 1b. The samples were fatigue pre-cracked and then pulled under displacement control mode until fracture, at a rate of $1 \mathrm{~mm} / \mathrm{min}$. The CTOD testing was conducted at room temperature in accordance with the ASTM: E 1820-11e2 standard. The CTOD defined for a gauge length of $5 \mathrm{~mm}\left(\delta_{5}\right)$ was measured on the specimen surface in the vicinity of the crack tip by using an object-grating method. Parallel to the CTOD measurements, the near crack tip deformations were monitored by ARAMIS GOM GmbH stereometric measuring system [25]. During loading, the displacements of random grating attached to the specimen surface were recorded by two CCD cameras with a resolution of $768 \times 572$ pixels and 256 gray levels. Displacements of the optical marks were then captured by digital processing algorithms of the ARAMIS system in a such way that the $3 \mathrm{D}$ displacement field measurements were obtained [26,27]. Using the stereometrical surface displacements, a load $(F)$ vs. crack tip opening displacement $\left(\delta_{5}\right)$ curve was plotted. Fig. 2 shows the images of undeformed and deformed grating structures of a specimen surface along with experimentally obtained $F v s$. $\delta_{5}$ curves. The measurement procedure and numerical analysis of obtained data are described in details elsewhere [26,27].

In order to develop $R$ curve, it is necessary to determine the crack extension $\Delta a$ during loading. Its determination by standard method requires using a crack mouth opening displacement $(C M O D)$ or load-line displacement $\left(C M O D_{L L D}\right)$ gauge [21]. However, the $C M O D$ values can be also estimated from the $3 \mathrm{D}$ displacement field measurements using a grating method. Namely, Gubeljak et al. [21] showed that $C M O D$ values taken from the displacement field measurements are exactly the same as those obtained by a 


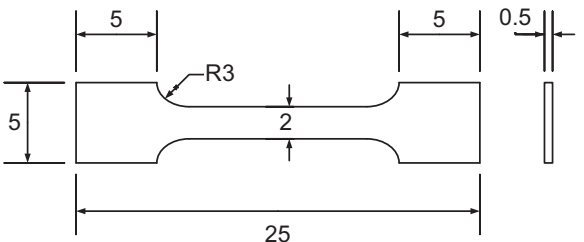

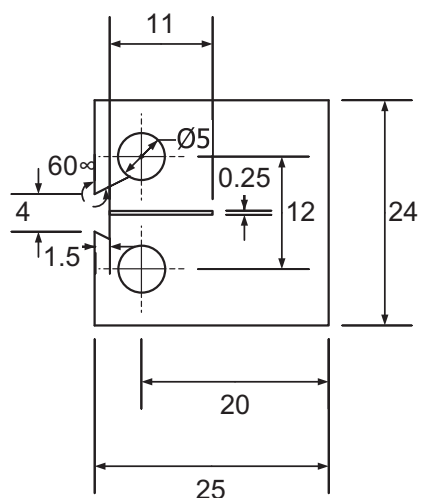

(b)

(a)

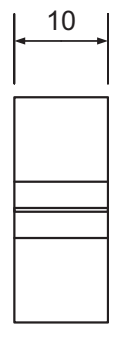

Fig. 1. Geometry of MTS (a) and CT (b) specimen (all dimensions are in millimeters).

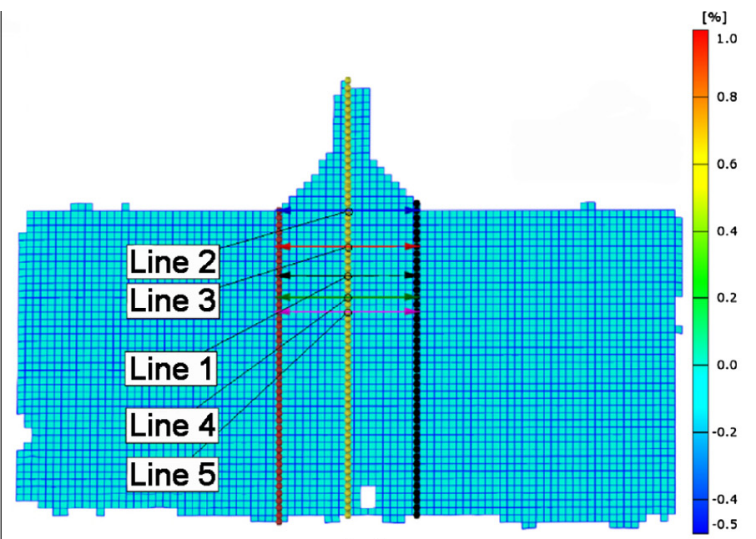

(a)

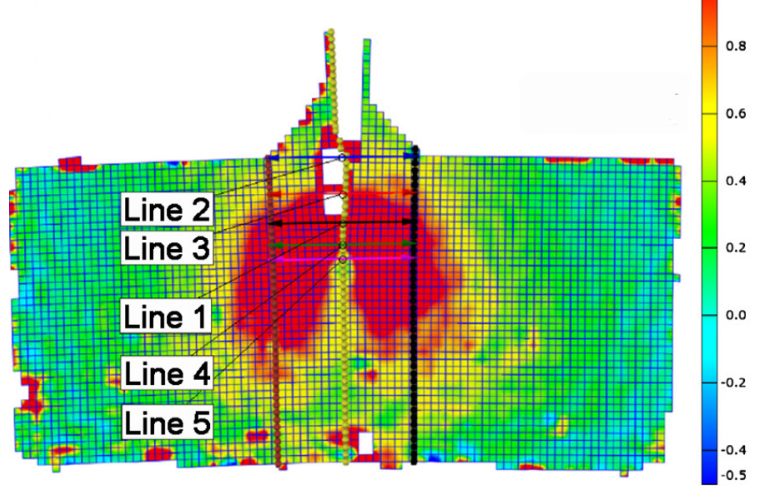

(b)

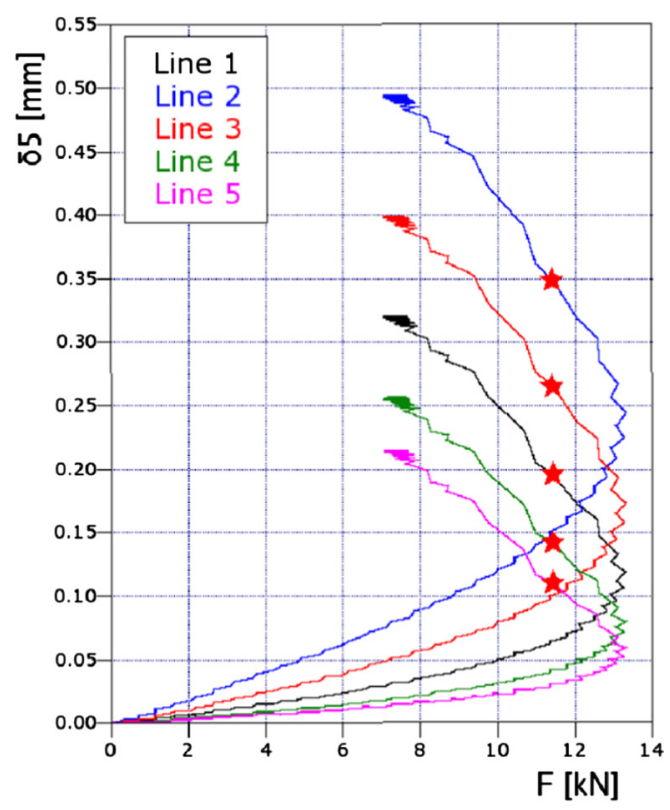

(c)

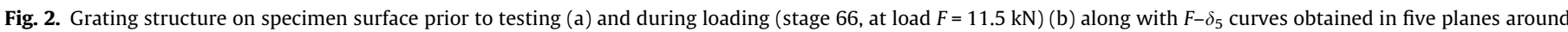
crack tip (lines 1-5) (c).

conventional CMOD clip gauge measurement technique. Therefore, the normalization method extended to the use of an indirect displacement was applied in our case for determination of the crack extension values. The resistance curve, $C T O D-\Delta a$, was obtained by the normalization procedure following the slightly modified ASTM: E 1820-11e2 standard (we applied a three fitting coefficients approach as utilized by Gubeljak and coworkers [21] in their studies). On the basis of the load-calculated CMOD curves, the values of plastic loading line displacement $\left(C M O D_{p l}\right)$ were obtained.
To find normalization parameters, the normalized load $\left(P_{N i}\right)$ was plotted as a function of $C M O D_{p l}$. As a final result, the $R$ curves for tested specimens were developed. For more details of applied normalized method see literature $[21,22]$. The obtained resistance curves were used for determining the values of CTOD at crack initiation $\left(C T O D_{i}\right)$ and crack extension of $0.2 \mathrm{~mm}$ after crack tip blunting $\left(C T O D_{0.2 / B L}\right)$.

To characterize the surface crack path in both full lamellar and equiaxed microstructures, the crack patterns at various loading 
steps were recorded using a digital camera. Fractographic post test examinations were conducted on the fracture surfaces of specimens using a light microscope (LM) and SEM operating in SEI mode at $20 \mathrm{keV}$. The fracture mechanisms and stretched zone width (SZW) were evaluated.

\section{Results and discussion}

\subsection{Microstructure and tensile properties}

Characteristic Ti-6Al-4V ELI alloy microstructures developed during continuous cooling from $\beta$ and $\alpha+\beta$ phase field are shown in Fig. 3. A fully lamellar microstructure with a grain boundary $\alpha$ phase and colonies of alternate layers of $\alpha$ and $\beta$ phase distributed in prior $\beta$ grains is formed by $\beta$ ST FC treatment (Fig. 3a). More of prior $\beta$ phase is transformed into $\alpha$ phase, so that this microstructure consists of 12.6 vol.\% prior $\beta$ and the remainder $\alpha$ phase. Due to the coarse prior $\beta$ grains and slow cooling from $1000{ }^{\circ} \mathrm{C}$ the resulting microstructure is rather coarse. The average lamellar colony size is $49.8 \mu \mathrm{m}$ within which a mixture of $\alpha$ and $\beta$ lamellas $3 \mu \mathrm{m}$ and $0.7 \mu \mathrm{m}$ in size, respectively, is formed.

After $\alpha+\beta$ ST FC treatment, the microstructure changed significantly (Fig. 3b). A two-phase microstructure with no appreciable difference in the amount of phases compared to fully lamellar microstructure is obtained. It consists of primary $\alpha$ grains and intergranular $\beta$ phase present in an amount of $\approx 14$ vol.\%. However, the microstructure formed during cooling from $750{ }^{\circ} \mathrm{C}$ shows completely different morphology. The equiaxed $\alpha$ grains can be distinguished in this microstructure. Their dimension is found to be almost the same to the width of $\alpha$ lamellas and equals to $2.9 \mu \mathrm{m}$. On the other hand, the decrease of the primary $\alpha$ grains aspect ratio and the change of $\alpha$ grains spacing from 0.7 to $1.1 \mu \mathrm{m}$ may contribute to different mechanical behavior.

Average values of tensile properties depending on the alloy microstructural morphology are given in Table 1 . It can be seen that the tensile behavior of heat treated alloy is influenced by microstructural characteristics in the great extent.

Namely, increase in solution treatment temperature from $750{ }^{\circ} \mathrm{C}$ to $1000^{\circ} \mathrm{C}$ and development of fully lamellar microstructure leads to evident decrease in all tensile properties. Compared with the alloy in $\alpha+\beta$ ST FC condition, the yield strength and ultimate tensile strength of the $\beta$ ST FC treated alloy are lower by $336 \mathrm{MPa}$ and $346 \mathrm{MPa}$, respectively. Their values also indicate that heat treatment in the $\beta$ field leads to smaller strain hardening $\left(R_{m}-\right.$ $R_{p 0.2}=36 \mathrm{MPa}$ ) than in the case of alloy heat treated in $\alpha+\beta$ field $\left(R_{m}-R_{p 0.2}=56 \mathrm{MPa}\right)$. In general, the slip length occurring during plastic deformation determines the resistance against dislocation motion and, consequently, the strength level. Decrease in effective slip length with refining of the microstructural dimensions leads to increase in tensile strength. Therefore, the enhancement in strength with the solution treatment temperature is primarily due to the microstructural refinement of the examined alloy. The higher strength of equiaxed microstructure is a result of a much shorter effective slip length in comparison with the fully lamellar microstructure. A similar width of the $\alpha$ lamellae and the primary $\alpha$ grain allows us to infer that the $\alpha$ colony size is the major microstructural parameter determining the tensile strength of fully lamellar microstructure. Since the colony size is more influential on the strength than the $\alpha$ lamellae width, the change of effective slip length from the lamellar colony width to the width of a single primary $\alpha$ grain contributes to a drastic increase in yield strength and ultimate tensile strength. This observation is in agreement with the results of Lee et al. [12] and Lütjering [7].

The equiaxed microstructure also exhibits the much higher elastic modulus. Its value is about $11 \mathrm{GPa}$ higher than that of fully lamellar microstructure, indicating that alloy in $\alpha+\beta$ ST FC condition has lower biomechanical compatibility with human bone. Since the implant elastic modulus greater than that of natural bone is associated with stress mismatching which leads to bone resorption and joint loosening, it is very important to increase a bone density by using a lower modulus device [5]. According to this, the fully lamellar microstructure tends to be beneficial in reducing adverse stress shielding effect.

However, the equiaxed microstructure shows better combination of strength, elastic modulus and ductility. Although this microstructure has high yield and tensile strength, its elongation to fracture is almost three times higher as compared with a fully lamellar microstructure. Decrease in effective slip length and higher amount of softer $\beta$ phase than in the fully lamellar microstructure contribute to the enhancement in alloy ductility.

\subsection{Fracture resistance}

The experimentally obtained $F v s$. $\delta_{5}$ measured by a stereometrical method and $F$ vs. CMOD curves for fully lamellar and equiaxed microstructures are shown in Fig. 4. The presented results prove that microstructural morphology has a great influence on the fracture resistance of the Ti-6Al-4V ELI alloy. Although the alloy in both heat treatment conditions is highly resistant to fracture, the

Table 1

Tensile properties of Ti-6Al-4V ELI alloy with different microstructures at room temperature.

\begin{tabular}{lllccrl}
\hline $\begin{array}{l}\text { Heat } \\
\text { treatment }\end{array}$ & Microstructure & $\begin{array}{l}E \\
(\mathrm{GPa})\end{array}$ & $\begin{array}{l}R_{p 0.2} \\
(\mathrm{MPa})\end{array}$ & $\begin{array}{l}R_{m} \\
(\mathrm{MPa})\end{array}$ & \multicolumn{1}{c}{$\begin{array}{l}A \\
(\%)\end{array}$} & $n$ \\
\hline $\begin{array}{l}\text { ST FC } \\
\alpha+\beta \text { ST FC }\end{array}$ & $\begin{array}{l}\text { Fully lamellar } \\
\text { Equiaxed }\end{array}$ & 124.8 & 737 & 773 & 5.4 & 0.03 \\
\hline
\end{tabular}

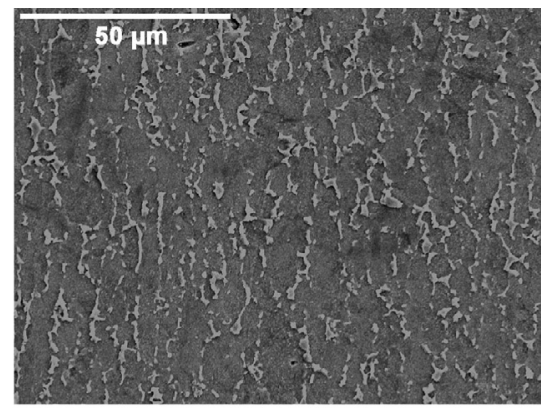

(b)

(a)

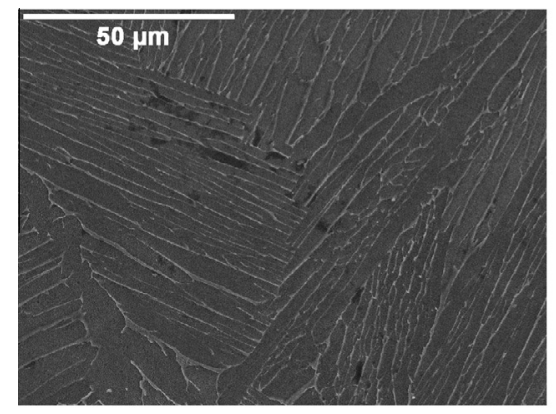

Fig. 3. SEM micrographs showing the Ti-6Al-4V ELI alloy microstructure obtained by $\beta$ ST FC (a) and $\alpha+\beta$ ST FC (b) treatment. Phase contrast: $\alpha$-gray, $\beta$-white. 
fully lamellar microstructure appears to display the better fracture properties.

The $R$ curves along with $P_{N i} v s$. $C M O D_{p l}$ diagrams are given in Fig. 5. The CTOD values are relatively high, regardless of the applied heat treatment. However, the CTOD of the alloy with equiaxed microstructure is lower than that of the fully lamellar microstructure. There is also a considerable difference in the shape of the fracture resistance curves particularly in the early stage of crack propagation. Such behavior is also experimentally observed by some authors [18]. The both crack initiation and crack propagation resistance are greatly dependent on the changes in the microstructure. In comparison to equiaxed microstructure, the fully lamellar microstructure results in significantly higher fracture resistance. The both $C T O D$ parameters indicating the crack initiation resistance show the same tendency with solution treatment temperature and in turn the microstructural morphology. The $C T O D_{i}$

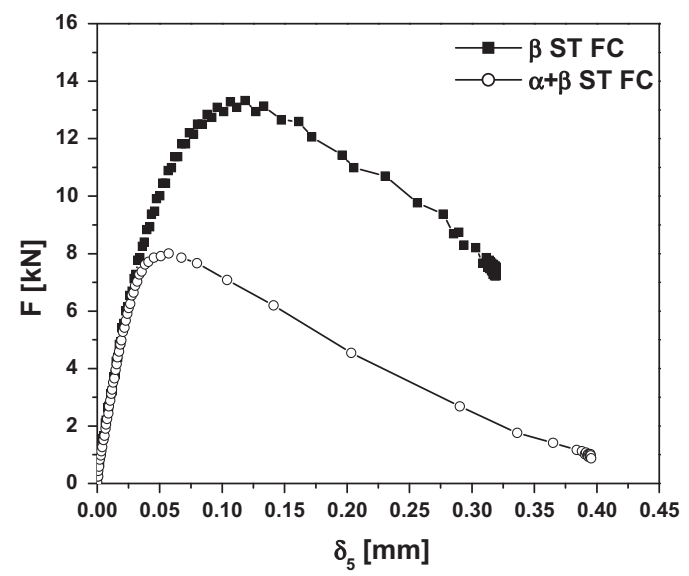

(a)

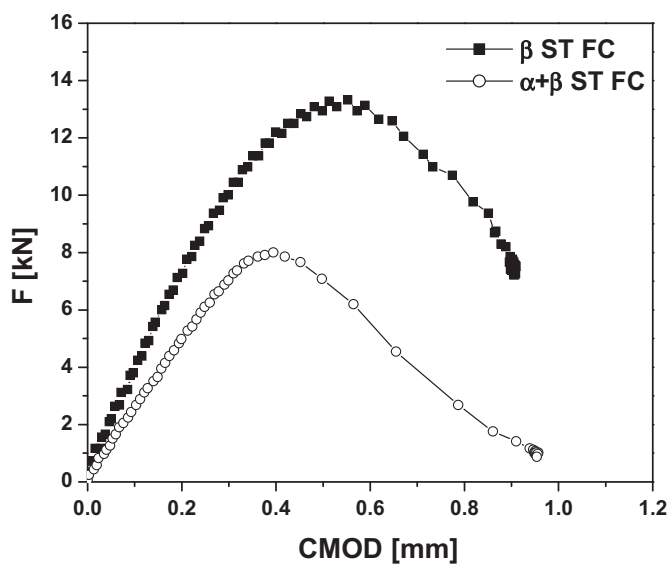

(b)

Fig. 4. $F$ vs. $\delta_{5}$ obtained in plane designated as line 1 (a) and $F$ vs. CMOD (b) curves for Ti-6Al-4V ELI alloy in different heat treatment conditions.

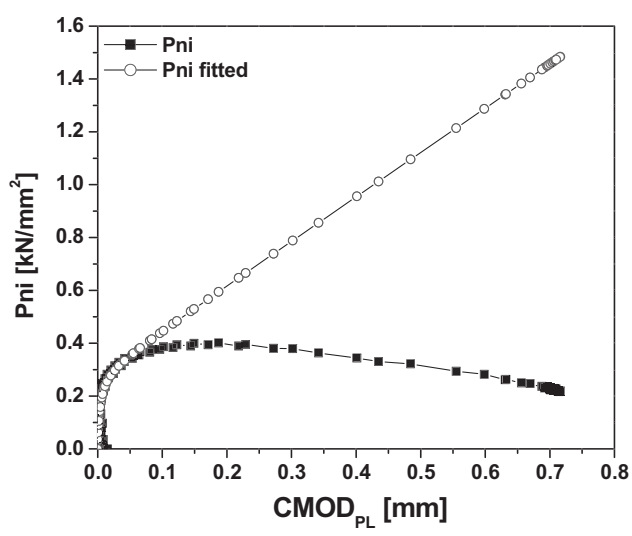

(a)

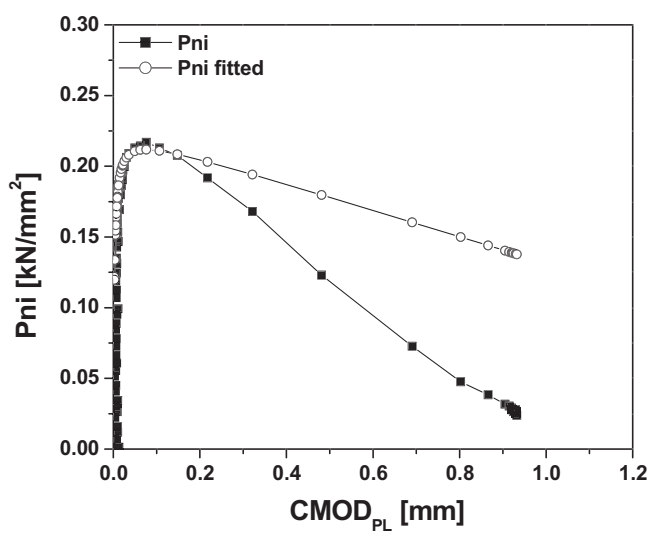

(b)

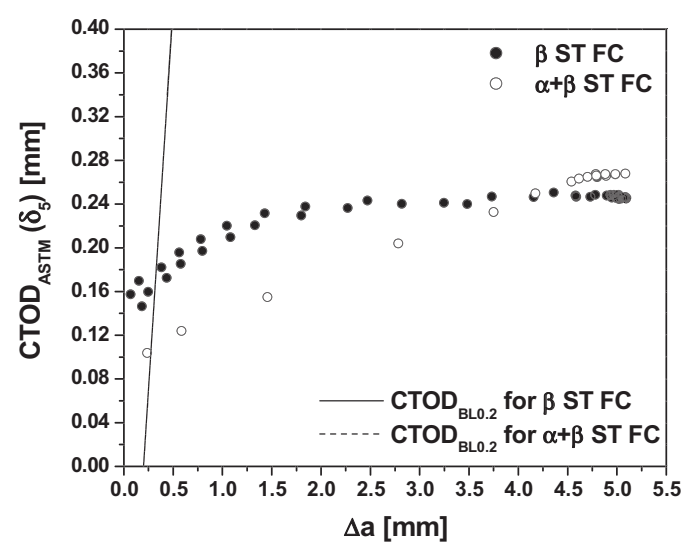

(c)

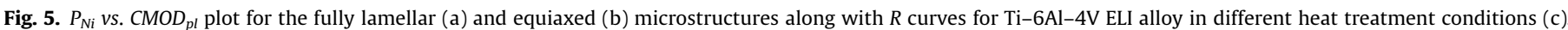


values obtained for the alloy in $\beta$ ST FC and $\alpha+\beta$ ST FC heat treatment condition are $0.158 \mathrm{~mm}$ and $0.090 \mathrm{~mm}$, respectively. Apparently, an increase of both $\beta$ phase volume fraction and $\alpha$ phase spacing, that is mean free path through $\beta$ matrix, decreases the crack initiation resistance of the examined alloy.

The values of $C T O D_{i}$ are determined by intersection of vertical axis with the $R$ curves, because it is assumed that the crack extension for blunting is small. The SEM examination of the fracture surfaces confirms this assumption. Namely, different macro fracture appearances shown in Fig. 6a and b indicate that the fracture features are strongly affected by the microstructural morphology. Detailed SEM observations of the fracture surface near the crack tip (Fig. 6c and d) reveal a narrow stretched zone, which is formed as a result of blunting and stretching at a crack tip during fracture process. Since the stretched zone is hardly observed especially in the case of the fully lamellar microstructure, extent of crack tip blunting is identified as a small. The value of SZW obtained for the equiaxed microstructure is $21.4 \mu \mathrm{m}$, while the stretched zone in the fully lamellar microstructure is not clearly visible and therefore it is not measured. This implies that the crack tip blunting in the fully lamellar microstructure is negligible, but it influences the fracture process in the equiaxed microstructure.

The $C T O D_{0.2 / B L}$ values of $0.182 \mathrm{~mm}$ and $0.104 \mathrm{~mm}$ are greater than the $C T O D_{i}$ ones. However, the fully lamellar microstructure has a greater $C T O D_{0.2 / B L}$ than the equiaxed microstructure. As can be seen, the critical CTOD values for the fully lamellar microstruc-

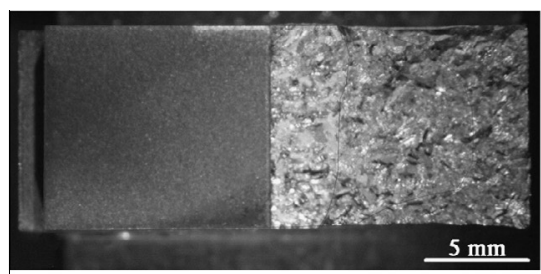

(a)

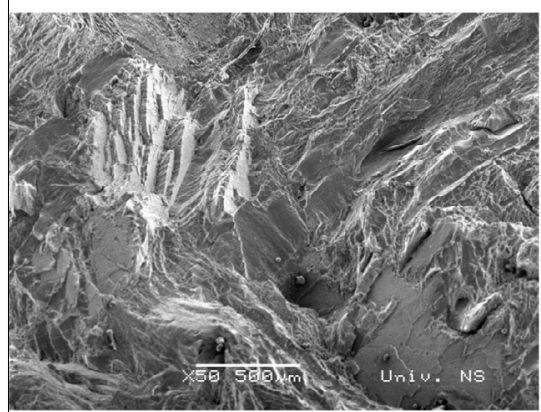

(c)

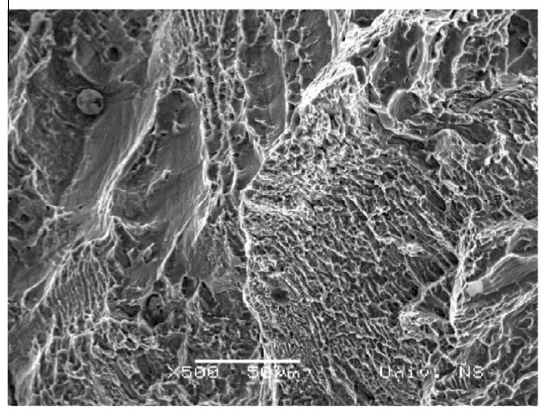

(e)

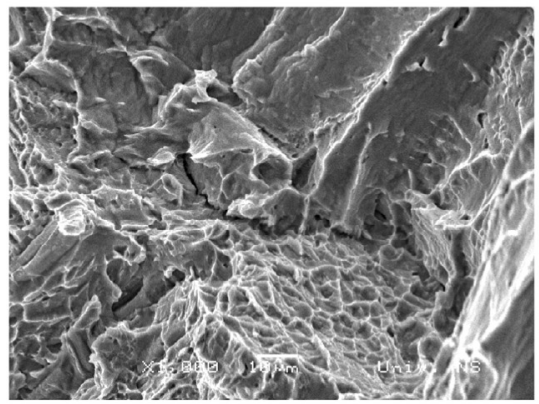

(g)

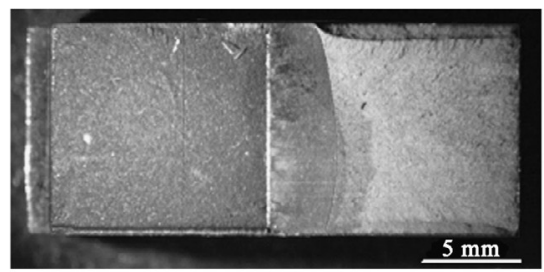

(b)

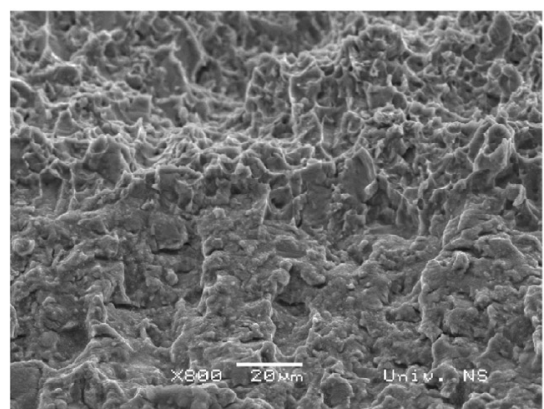

(d)

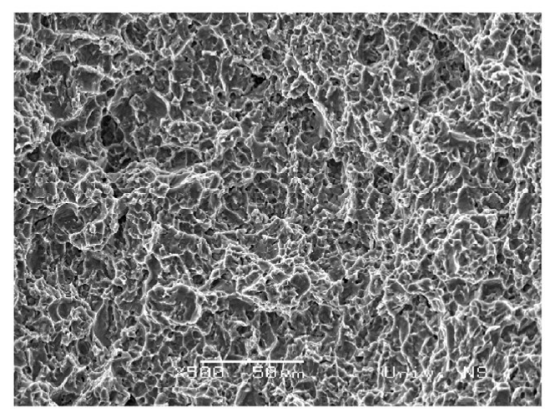

(f)

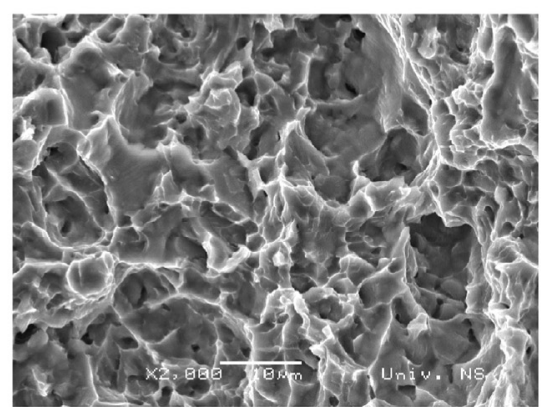

(h)

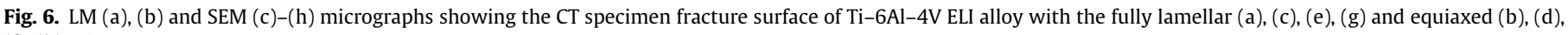
(f), (h) microstructure. 
ture are almost two times higher than for the equiaxed microstructure. This is consistent with a much lower yield strength exhibited by the fully lamellar microstructure. Namely, the crack opening displacement $(C O D)$ depends on the extent of straining in the plastic zone ahead of the crack tip and decreases sharply with increasing yield strength [28]. Since the local ductility is a measure of the critical strain for the onset of crack propagation, its reduction contributes to the loss in fracture toughness. The strain hardening reduces sensitivity to localization and hence reduces COD.

From obtained $R$ curves, it is evident that alloy with fully lamellar microstructure also shows a higher resistance to crack propagation which can be attributed to the $\alpha$ phase morphological changes. The gradient of $R$ curves is obviously different and increases as the equiaxed morphology of $\alpha$ phase changes to the lamellar one. Horiya and Kishi [18] reported that this difference in CTOD values, especially at small crack extensions, is related with the existence of the microcracks extended from the notch tip before the maximum load. In order to explain crack propagation behavior of the alloy, we combine in situ observations of surface crack extension during loading and fractographic examinations of the fracture surfaces morphology. Because the crack advance is controlled by the size of the plastic zone ahead of the crack tip, strain distributions around the crack tip at various loading stages are recorded.

\subsection{Crack tip strain distribution and crack propagation path}

Figs. 7 and 8 show the crack patterns at various loading levels and diagrams of corresponding strain distribution around the crack tip. During the stereometric test the load was tracked at 78 (equiaxed microstructure) and 98 (fully lamellar microstructure) levels. It is observed that the strain at the crack tip is higher than in the rest of the specimen surface. Also, the size and shape of the crack tip strain field varies with a crack propagation mode. In the case of the fully lamellar microstructure, the large plastically deformed zone is established. Plastic zone of significant size and with a deviation angle between its maximum dimension $r_{\max }$ and symmetrical axis of $\approx 45^{\circ}$ is visible even at low loading levels (Fig. $7 \mathrm{~b}, \mathrm{~d}, \mathrm{f}$ and $\mathrm{h}$ ). As the load increases the plastically deformed zone in the vicinity of crack tip increases, as well and a change in its shape becomes more and more evident. Namely, angle between direction of the maximum plastic zone dimension $r_{\max }$ and crack propagation direction reduces. The observed changes in the plastic zone size are associated with the onset of crack extension and subsequent crack advance. Fig. 7a depicts the pattern of specimen surface near the crack tip when microcrack is initiated. From Fig. 7c, it is apparent that microcrack is extended before the maximum load $F_{\max }$ is reached. Expanded microcrack is inclined to the main crack propagation direction and extends further with increasing loads. Near the $F_{\text {max }}$, the path of surface crack propagation changes and becomes less tortuous (Fig. 7e). Final fracture develops when the crack trajectory is significant in length (Fig. $7 \mathrm{~g}$ ).

Different behavior is observed for the equiaxed microstructure. In this case, the actual crack path is rather flat (Fig. 8a, c, e and g). As can be seen, a small load does not lead to microcrack development. The plastic flow at the crack tip blunts the crack and microcrack does not appear until load reaches value near the $F_{\max }$, which is significantly smaller then in the case of the fully lamellar microstructure. The microcrack extends with increasing load, but at load just before the $F_{\max }$ the unstable fracture occurs, so that the length of the microcrack extension before the main crack development is comparatively small. Due to the crack tip blunting exhibiting the strong effect on the crack tip strain field, the plastic zone ahead of the crack tip is smaller than in the case of the fully lamellar microstructure (Fig. 8b). The higher loading level, the larger the plastic zone size (Fig. 8d and f). However, the extent of the plastic zone is smaller in the equiaxed microstructure than in the fully lamellar one for the same loading level. Further, a deviation angle of the $r_{\max }$ direction is lower than $45^{\circ}$ and has a tendency to decrease with increasing loads. Thus, the $r_{\max }$ direction of the plastic zone makes a lower angle with the crack propagation direction than in the case of the fully lamellar microstructure, corresponding to a flat appearance of the crack path (Fig. 8h). This can be attributed to the difference in the strain hardening exponent $n$ of the two microstructures (see Table 1) according to Dodds et al. [29], who examined the influence of $n$ value on the plastic zone shape by using finite element method (FEM) calculations.

These observations indicate the significant influence of near tip microstructure on the local crack path. The critical microstructural feature controlling the crack propagation has different dimensions. This can be explained by a fact that a crack prefers the damaged microconstituents enclosed in the plastic zone [30]. The larger the plastic zone size, the greater the amount of microconstituent boundary areas is falling within it. The lamellar colony size is found to be this critical feature in the case of the fully lamellar microstructure, which is characterized by a larger plastic zone. The $\alpha$ lamellae boundaries provide fairly low resistance to the crack propagation, so that crack extends by interlamellar or translamellar fracture and changes direction when crossing the colony boundaries. The changes in the crack direction cause the crack branching and secondary crack formation, so that crack propagation through the differently oriented neighboring colonies requires additional energy. As the colony boundaries become the effective obstacles for the crack propagation, they play an important role in the crack propagation response of this microstructure. Thus, the propensity for crack path tortuousity and in turn crack propagation resistance increases with increasing lamellar colony size. In the finer-scale equiaxed microstructure, the primary $\alpha$ grain size becomes the microstructural feature controlling the crack propagation resistance. With increasing applied load, the plastic zone grows until it becomes large enough to provide the crack propagation along the primary $\alpha$ grain boundaries. Additionally, a lower aspect ratio of the primary $\alpha$ grain contributes to the decrease of the crack deflection. Since the lamellar colonies are more than one order of magnitude larger than primary $\alpha$ grains, the crack path in the fully lamellar microstructure is more tortuous improving the crack propagation resistance of the $\beta$ ST FC treated alloy. This is in accordance with the results of Nakajima et al. [31], who reported that the change of primary $\alpha$ grain size even from $2.2 \mu \mathrm{m}$ to $5.5 \mu \mathrm{m}$ increases crack deflection and in turn crack propagation resistance of the $\alpha+\beta$ type Ti-4.5Al-3V-2Mo-2Fe alloy. In the present investigation, the reduced crack path deflection across the primary $\alpha$ grain boundaries results in more straight crack propagation path and less rough fracture surface, as shown by SEM micrographs in Fig. 6c-h.

\subsection{Fracture mechanisms}

It can be noted that the differences in the fracture surface roughness between two microstructures are quite significant. The fracture surface for the fully lamellar microstructure is very rough, with long and relatively high cleavage steps ahead the stretched zone (Fig. 6c). The damage mechanism is predominantly transgranular quasi-cleavage fracture through the colonies (Fig. 6e). Namely, the large quasi-cleavage facets surrounded by ridges at which the crack changes propagation direction are almost equal to the lamellar colony size. The presence of fine and relatively deep transgranular dimples mixed with intergranular dimples clustered in very narrow areas parallel to the long axis direction of the $\alpha$ lamellas suggests that the fracture process is complex and involves different mechanisms. Numerous microvoids initiated preferentially at the $\alpha / \beta$ lamellar interfaces and secondary cracks created by their linkage are observed on the fracture surface (Fig. $6 g$ ), indicating the 


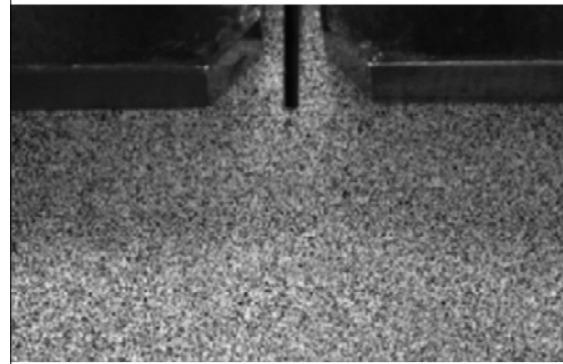

(a)

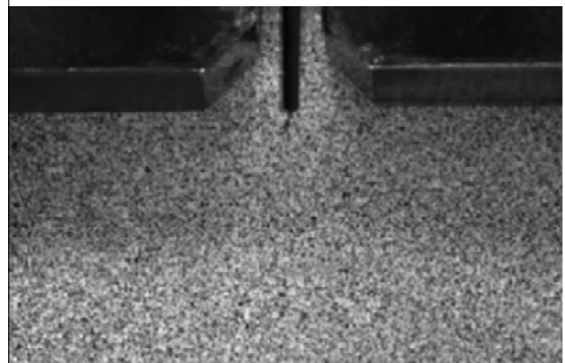

(c)

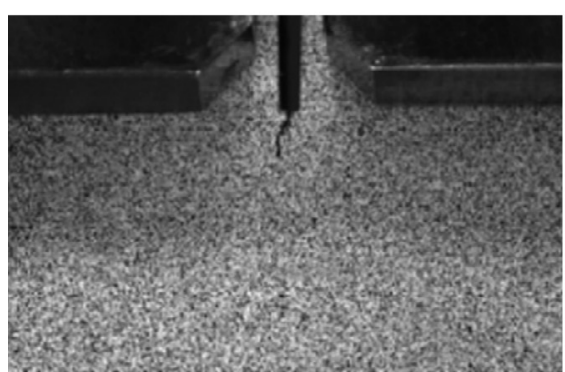

(e)

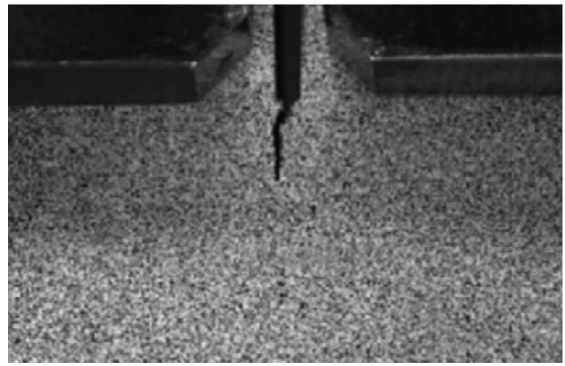

(g)

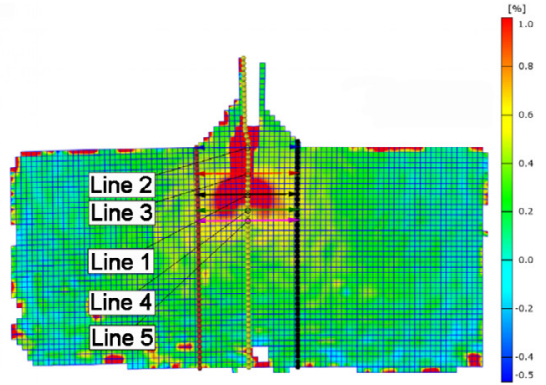

(b)

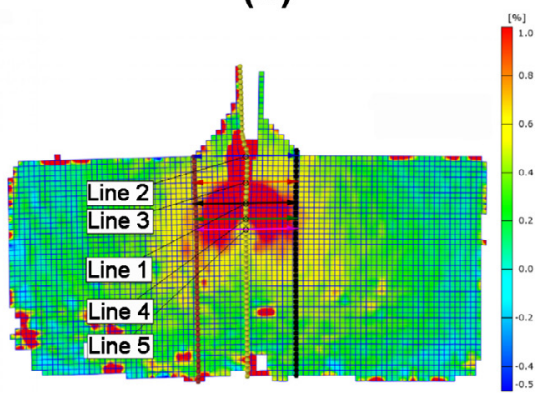

(d)

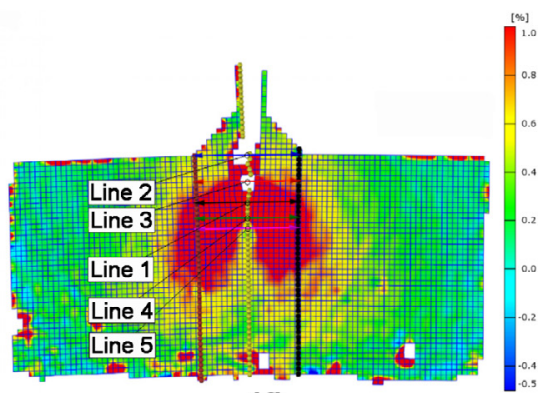

(f)

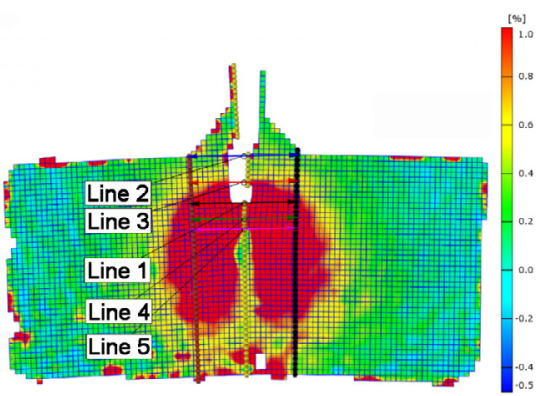

(h)

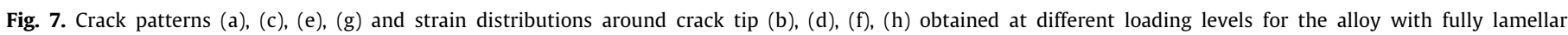
microstructure. (a), (b) Stage $45, F=11.0 \mathrm{kN}$, (c), (d) stage $56, F=13.0 \mathrm{kN}$, (e), (f) stage $65, F=12.0 \mathrm{kN}$ and (g), (h) stage $98, F=7.5 \mathrm{kN}$.

crack propagation direction. As the most microvoids nucleate before cracking at $\beta$ side of the $\alpha / \beta$ interface, the crack deviates around $\alpha$ lamellas. Richards [17] reported that the crack would deviate past the colony or around $\alpha$ platelets if the energy to fracture the $\alpha$ platelets is greater than that involved in circumventing the $\alpha$ colony. Otherwise the crack would propagate through $\alpha$ platelets.

Helbert et al. [32] experimentally and numerically investigated damage initiation and kinetics in different $\alpha / \beta$ titanium alloys and identified the nucleation limits of voids located at the $\alpha / \beta$ interfaces. They showed that the triaxiality and plastic strain have a strong influence on the nucleation strain for this kind of voids. The nucleation plastic strain increases with hydrostatic stress $\sigma_{m}$ decreasing. On the other hand, the $\sigma_{m}$ needed for void nucleation at the $\alpha / \beta$ interface decreases when saturated internal stress increases. In other words, with high internal stress, less hydrostatic stress will be necessary to rich the critical nucleation stress. Hence, low internal stresses delay void initiation and break down damage development. Same authors also demonstrated that the strainstress distribution near the $\alpha / \beta$ interface depends on the amount and aspect ratio of $\alpha$ phase. The saturated internal stress is maximal for $60-70 \%$ of $\alpha$ phase. With further increasing of the $\alpha$ phase volume fraction, saturated internal stress decreases. However, a change in the $\alpha$ phase morphology results in the saturated internal stress modification. An increase of its aspect ratio increases the saturated internal stress and modifies the volume fraction of the $\alpha$ 


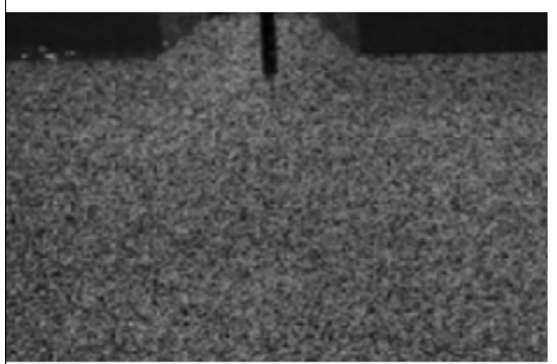

(a)

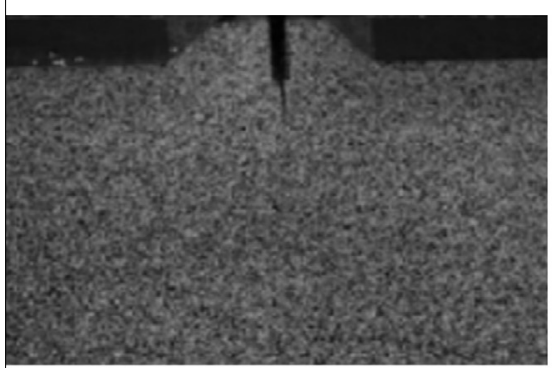

(c)

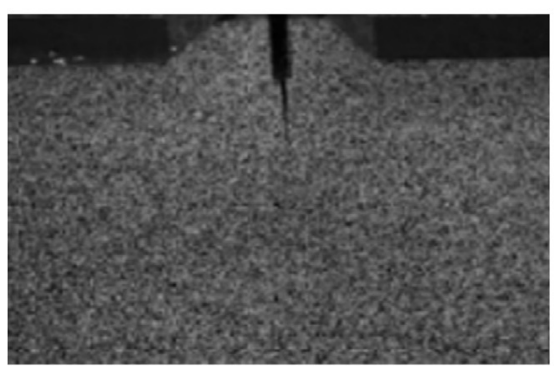

(e)

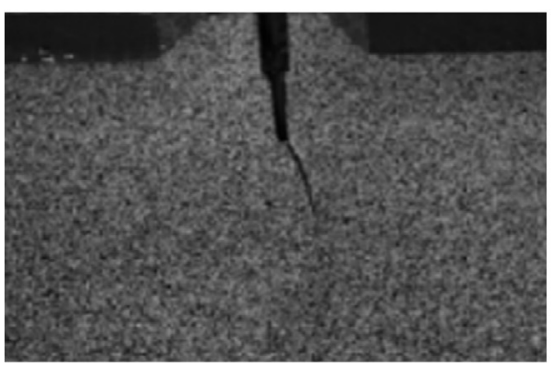

(g)

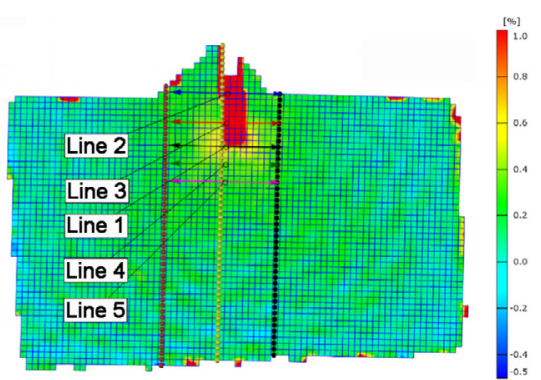

(b)

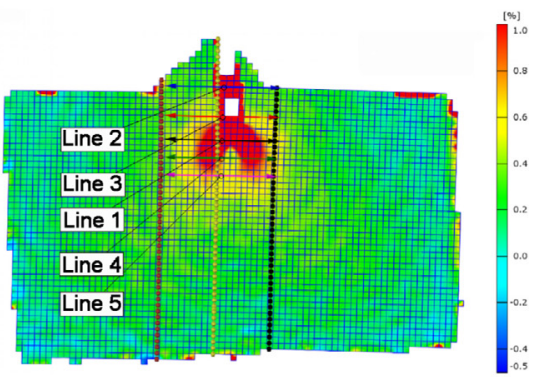

(d)

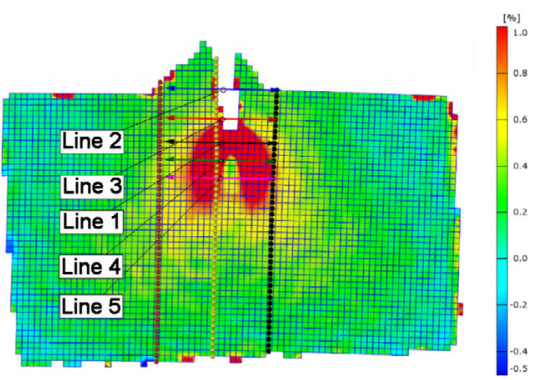

(f)

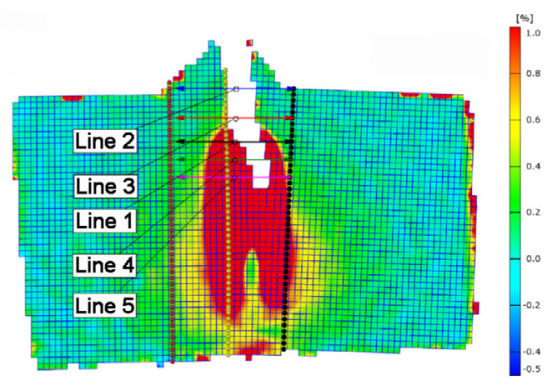

(h)

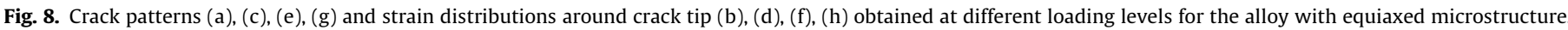
(a), (b) Stage $43, F=5.5 \mathrm{kN}$, (c), (d) stage $57, F=8.0 \mathrm{kN}$, (e), (f) stage $60, F=7.0 \mathrm{kN}$ and (g), (h) stage $78, F=1.5 \mathrm{kN}$.

phase for which the internal stress has a maximum value [32]. As a result, the local hydrostatic stress for microvoid nucleation will be smaller in the acicular microstructure with the greater amount of the $\alpha$ phase distributed over shorter distances. From these observations, it appears that the microvoids initiate earlier in the fully lamellar microstructure. The lower yield stress and strain hardening rate then in the case of equiaxed microstructure accelerate the onset of the microvoid growth and coalescence process, so that interlinking of microvoids occurs more readily. However, developed microcracks do not link up with the main crack before the $F_{\max }$ is reached. The large scale meandering slows the main crack propagation, contributing beneficially to fracture resistance.
The overall appearance of $\alpha+\beta$ ST FC treated alloy fracture surface is very flat (Fig. 6f), due to the refined equiaxed microstructure. However, the damage mechanisms associated with the cracking process are of the same kind as those in the fully lamellar microstructure: quasi-cleavage and dimple fractures (Fig. 6h). The size of quasi-cleavage facets is comparable to primary $\alpha$ grain size dimension, while ductile fracture with void nucleation, growth and coalescence is governed by the globular $\beta$ grains. Transgranular dimples mixed with dimples on the walls of the ridges are larger compared with those of the fully lamellar microstructure, which indicates that the crack path is strongly affected by the primary $\alpha$ grain size, $\lambda_{\alpha}$, and spacing between primary $\alpha$ grains, $\lambda_{\beta}$. The coarse and deep dimples located at the boundaries between planar 
facets and surrounded areas with smaller dimples suggest that the voids arise at the $\alpha / \beta$ interfaces in the first stage of plastic flow. The larger number of microvoids also observed along the $\alpha / \beta$ interfaces (Fig. 6h) indicates that these dimples nucleate in greater fraction than in the fully lamellar microstructure. This is in agreement with the results of Helbert et al. [32]. If the $\alpha$ phase volume fraction is lower and in turn internal stresses are greater, the void initiation appears to be quicker. However, their growth is less pronounced due to the local stress state [33]. Only a few short secondary cracks are visible on the fracture surface (Fig. 6f). As discussed above, the yield stress and strain hardening influence the void growth and coalescence process. Also, the crack tip blunting changes the local triaxiality rate, involving in void growth [32]. In addition, the void coalescence is highly dependent on the initial void spacing which is attributed to a change in the initial aspect ratio of the voids $[32,34,35]$. At the earlier stage of plastic strain the void growth produces spherical voids, irrespective of the void initiation site. With strain increasing, the shape of voids changes so that most of them become elliptic in shape. The existence of the some ellipticalshaped microvoids near the notch tip is evident in both the fully lamellar and equiaxed microstructures of Ti-6Al-4V alloy [18]. However, these microvoids observed in equiaxed microstructure coalesced at the notch front just when the maximum load is attained and a main crack developed from the notch tip, resulting in unstable fracture.

\section{Conclusions}

Fracture resistance and crack tip strain distribution in Ti-6Al4V ELI alloy with fully lamellar and equiaxed microstructure were examined in order to identify the most important microstructural parameter determining the damage behavior of this alloy for biomedical applications. From the obtained results, the following conclusions can be made:

(1) The difference in applied heat treatments significantly affects the tensile and fracture properties of investigated $\alpha+\beta$ titanium alloy. The decrease of solution treatment temperature from $1000{ }^{\circ} \mathrm{C}$ to $750{ }^{\circ} \mathrm{C}$ results in finer-scale microstructure, showing a changed volume fraction and morphology of the individual phases. The fully lamellar microstructure with $87 \mathrm{vol} . \%$ of the $\alpha$ phase and the $\alpha$ colonies $\approx 50 \mu \mathrm{m}$ in size developed during slow cooling from $1000{ }^{\circ} \mathrm{C}$ changes in the equiaxed microstructure with 86 vol.\% of the primary $\alpha$ phase $2.9 \mu \mathrm{m}$ in size.

(2) The refinement of microstructure improves the tensile properties. The equiaxed microstructure exhibits the significantly higher yield strength, ultimate tensile strength, elastic modulus and elongation to fracture due to the decrease in effective slip length that is more than one order of magnitude less than in the lamellar microstructure. However, the fully lamellar microstructure possesses better tensile strength/elastic modulus combination, which may be beneficial in improving biomechanical compatibility.

(3) The fully lamellar microstructure also has a beneficial effect on the fracture resistance. The critical CTOD values and $R$ curves show that this microstructure, having a coarser characteristic microstructural dimensions, displays superior crack initiation and propagation resistance to the equiaxed one. This improvement is governed by much lower yield strength, smaller strain hardening effect and morphological characteristics of the fully lamellar microstructure.

(4) Among all microstructural parameters the $\alpha$ colony size and aspect ratio of the $\alpha$ phase have the strongest influence on the fracture behavior of the fully lamellar microstructure. The increase of the crack deflection and more tortuous crack path, resulting in rougher fracture surface, improve the crack propagation resistance. In the case of the equiaxed microstructure the primary $\alpha$ grain size is critical microstructural feature controlling the crack propagation path and resistance.

(5) The appearance of the crack is associated with the extent of the plastic zone ahead of the crack tip. Smaller plastically deformed zone corresponds to a flat crack path in the case of the equiaxed microstructure. Differences in the plasticity levels at the crack tip result in more blunted crack tip in the equiaxed microstructure The application of digital stereometric method enables the accurate determination of actual crack tip strain distribution along with stable crack initiation.

(6) The complex fracture process involves two main mechanisms: quasi-cleavage and dimple fractures. The dominant fracture mode varies with microstructural morphology, leading to difference in the fracture surface roughness. In the fully lamellar microstructure the transgranular quasicleavage fracture is predominant damage mechanism, while ductile fracture characterized by the void nucleation and growth at the $\alpha / \beta$ interfaces is most significant in the equiaxed microstructure.

\section{Acknowledgements}

This work was financially supported by the Ministry of Education, Science and Technological Development of the Republic of Serbia through the Project No. 174004. The authors would like to acknowledge Dr. Jožef Predan from Faculty of Mechanical Engineering, University of Maribor, Slovenia for his help in the experimental work.

\section{References}

[1] Silver FH. Biomaterials, medical devices and tissue engineering: an integrated approach. London: Chapman \& Hall; 1994.

[2] Geetha M, Singh AK, Asokamani P, Gogia AK. Ti based biomaterials, the ultimate choice for orthopaedic implants - a review. Progr Mater Sci 2009;54:397-425.

[3] Long M, Rack HJ. Titanium alloys in total joint replacement - a materials science perspective. Biomaterials 1998;19:1621-39.

[4] Rack HJ, Qazi JI. Titanium alloys for biomedical applications. Mater Sci Eng C 2006;26:1269-77.

[5] Lin C-W, Ju C-P, Chern Lin J-H. A comparison of the fatigue behavior of cast Ti7.5Mo with c.p. titanium, To-6Al-4V and Ti-13Nb-13Zr alloys. Biomaterials 2005;26:2899-907.

[6] Niinomi M. Mechanical biocompatibilities of titanium alloys for biomedical applications. J Mech Behav Biomed Mater 2008;1:30-42.

[7] Lütjering G. Influence of processing on microstructure and mechanical properties of $(\alpha+\beta)$ titanium alloys. Mater Sci Eng A 1998;243:32-45.

[8] Filip R, Kubiak K, Ziaja W, Sieniawski J. The effect of microstructure on the mechanical properties of two-phase titanium alloys. J Mater Process Technol 2003;133:84-9.

[9] Weiss I, Semiatin SL. Thermomechanical processing of alpha titanium alloys an overview. Mater Sci Eng A 1999;263:243-56.

[10] Ghonem H. Microstructure and fatigue crack growth mechanisms in high temperature titanium alloys. Int J Fatigue 2010;32:1448-60.

[11] Ding R, Guo YX, Wilson A. Microstructural evolution of a Ti-6Al-4V alloy during thermomechanical processing. Mater Sci Eng A 2002;327:233-45.

[12] Lee RD-G, Lee S, Lee CS, Hur S. Effects of microstructural factors on quasi-static and dynamic deformation behaviors of Ti-6Al-4V alloys with Widmanstätten structures. Metall Mater Trans A 2003;34A:2541-8.

[13] Peters JO, Lütjering G. Comparison of the fatigue and fracture of $\alpha+\beta$ and $\beta$ titanium alloys. Metall Mater Trans A 2001;32A:2805-18.

[14] Campbell JP, Ritchie RO. Mixed-mode, high-cycle fatigue-crack-growth thresholds in Ti-6Al-4V: role of bimodal and lamellar microstructures. Metall Mater Trans A 2001;32A:497-503. 
880

I. Cvijović-Alagić et al./Materials and Design 53 (2014) 870-880

[15] Nola RK, Bryce BL, Campbell JP, Peters JO, Ritchie RO. Influence of microstructure on high-cycle fatigue of Ti-6Al-4V: bimodal vs. lamellar structures. Metall Mater Trans A 2002;33A:899-918.

[16] Whittaker MT, Evans WJ, Lancaster R, Harrison W, Webster PS. The effect of microstructure and texture on mechanical properties of Ti6-4. Int J Fatigue 2009;31:2022-30.

[17] Richards NL. Quantitative evaluation of fracture toughness-microstructural relationships in alpha-beta titanium alloys. J Mater Eng Perform 2004;13(2):218-25.

[18] Horiya T, Kish T. Relationship between fracture toughness and crack extension resistance curves ( $R$ curves) for Ti-6Al-4V alloys. Petal Mater Trans A 1998;29A:781-9.

[19] Katani S, Madadi F, Atapour M. Micromechanical modeling of damage behaviour of Ti-6Al-4V. Mater Bes 2013;49:1016-21.

[20] Gunawarman A, Niinomi M, Fukunaga K-I, Eylon D, Fujishiro S, Ouch C. Fracture characteristics and microstructural factors in single and duplex annealed Ti-4.5Al-3V-2Mo-2Fe. Mater Sci Eng A 2001;308:216-24.

[21] Gubeljak N, Chapetti MD, Predan J, Landes JD. CTOD-R curve construction from surface displacement measurements. Eng Fact Mech 2011;78:2286-97.

[22] Cvijović-Alagić I.Lj. Damage and fracture resistance of titanium based alloys for medical application, Ph.D. Thesis, University of Belgrade; 2013.

[23] Cvijović-Alagić I, Rakin M, Cvijović Z, Gubeljak N, Gerić K. Microstructural effects on the mechanical properties and tribological damage of Ti-6Al-4V alloy. In: Proceedings of the First International Conference on Damage Mechanics (ICDM1). Belgrade, Serbia; 25-27 June 2012. p. 93-6.

[24] Schwalbe KH. Basic engineering methods of fracture mechanics and fatigue. Geesthacht: GKSS Research Center, Germany; 2001.
[25] ARAMIS v6, GOM GmbH, Braunschweig, Germany. 2007.

[26] Gubeljak N, Semenski D, Drvar N, Predan J, Kazak D, Oblak M. Object grating method application in strain determination on CTOD tests. Strain 2006;42(2):81-7.

[27] Gubeljak N. Application of stereometric measurement on structural integrity. Struct Integrity Life 2006;6(1-2):65-74.

[28] Sen I, Tamirisakandala S, Miracle DB, Ramamurty U. Microstructural effects on the mechanical behavior of B-modified Ti-6Al-4V alloys. Acta Mater 2007;55:4983-93.

[29] Bods RH, Anderson TL, Kirk MT. A framework to correlate a/W ratio effects on elastic-plastic fracture toughness $\left(J_{c}\right)$. Int J Fact 1991;48:1-22.

[30] Ladon DA, Apelian D, Major JF. Fatigue crack growth mechanisms at the microstructure scale in $\mathrm{Al}-\mathrm{Si}-\mathrm{Mg}$ cast alloys: mechanisms in regions II and III. Metall Mater Trans A 2006;37A:2405-18.

[31] Nakajima K, Terao K, Miyata T. The effect of microstructure on fatigue crack propagation of $\alpha+\beta$ titanium alloys: in situ observation of short fatigue crack growth. Mater Sci Eng A 1998;243:176-81.

[32] Hebert AL, Feaugas X, Claver M. Effects of microstructural parameters and back stress on damage mechanisms in $\alpha / \beta$ titanium alloys. Anta Mater 1998;46:939-51.

[33] Asserin-Lebert A, Besson J, Gourgues AF. Fracture of 6056 aluminum sheet materials: effect of specimen thickness and hardening behavior on strain localization and toughness. Mater Sci Eng A 2005;395:186-94.

[34] Pardoen T, Hutchinson JW. An extended model for void growth and coalescence. J Mech Phys Solids 2000;48:2467-512.

[35] Pardoen T, Hutchinson JW. Micromechanics-based model for trends in toughness of ductile metals. Anta Mater 2003;51:133-48. 